\title{
Deriving century-long trends of surface temperature change from borehole temperatures
}

\author{
Shaopeng Huang', Po Yu Shen', and Henry N. Pollack'
}

Abstract. We have employed few-parameter estimation (FPE) technique to derive information on past surface temperature variations from present-day borehole temperatures. Synthetic experiments show that the FPE technique can separate reasonably well information on century-long trends of surface temperature change from borehole temperatures within a wide range of noise levels. The technique also allows a simple illustration and comparison of the inversion results, both spatially and temporally. We illustrate this technique by analyzing seventeen borehole temperature profiles from eleven sites in northeast USA and southeast Canada, utilizing a ground surface temperature model of five ramps of century-long duration.

\section{Introduction}

Many recent efforts in deriving climate information from borehole temperatures have been focused on reconstructing a ground surface temperature history as a smooth arbitrary function over the whole time window of interest [e.g., Beltrami and Mareschal, 1991, MacAyeal et al., 1991, Shen and Beck, 1991, 1992; Wang, 1992; Wang et al., 1992; Wang and Lewis, 1992; Beltrami et al., 1992; Harris and Chapman, 1995; Shen et al., 1995a,b; Clauser and Mareschal, 1995]. We call such an approach an arbitrary function reconstruction (AFR). Here we present our experiments with a simplified approach, an estimation technique in which we characterize a general pattern of surface temperature variation with only a few parameters. These parameters include a reference baseline temperature (the long-term mean surface temperature existing prior to recent temperature excursions) and the average rate of temperature change over a few pre-selected time intervals. The true ground surface temperature history is thus approximated by several ramps of temperature change.

The main considerations which lead us to utilize this fewparameter estimation (FPE) technique include:

1. The resolving power of a borehole temperature profile for ground surface temperature reconstruction. Because of the amplitude attenuation of thermal diffusion and the inevitable presence of observational and representational noise in borebole data [e.g., Lewis and Wang, 1992; Shen et al., 1995a], a robust estimation can often be made for only a few parameters such as the trend, duration and the overall amplitude of the ground surface temperature change in the past [Clow, 1992; Chisholm and Chapman, 1992; Shen et al., 1995a; Beltrami and Mareschal, 1995].

\footnotetext{
1 Department of Geological Sciences, University of Michigan, Ann Arbor, Michigan, USA.

${ }^{2}$ Department of Earth Sciences, University of Western Ontario, London, Canada.
}

Copyright 1996 by the American Geophysical Union.

Paper number $96 \mathrm{GL} 00020$

0094-8534/96/96GL-00020\$03.00
2. The need to simplify and standardize the procedures for the reconstruction of ground surface temperature history. The problem of inverting borehole temperatures to yield a ground surface temperature history is an ill-posed problem, and therefore some constraints are required for a stable solution to emerge from data processing. As a consequence of this, inversion results are to some degree technique and researcher dependent [Beck et al., 1992; Shen et al., 1992; Shen et al., $1995 \mathrm{a}, \mathrm{b}]$. To allow a more consistent comparison of geothermally derived climate information, some kind of standardization of surface temperature reconstruction is desirable. But the standardization has not been an easy task in an AFR [Shen et al., 1995a, 1995b], partly because of the high degrees of freedom in representing a ground surface temperature history. We hope that the FPE technique will serve as a step towards the standardization of reconstruction, by identifying and estimating fewer parameters for comparison.

3. Convenience in comparing results. An AFR technique attempts to reconstruct a ground surface temperature history at time scales and degrees of detail that vary with time. But in many cases, particularly in a continent-wide or global study, one wishes to compare only general features instead of the details of ground surface temperature histories obtained from different areas. The FPE technique, which seeks only a few century-long trends of temperature change, will allow an easier comparison and illustration of the results.

A special case of a ground surface temperature model with few parameters is that of a simple power function given by Carslaw and Jaeger [1959] and applied by Cermak [1971] and Lachenbruch and Marshall [1986]. It is of course possible to make any of the AFR techniques an FPE technique by employing only a few time intervals in a time domain method, or a few frequencies in a spectral approach. Or algorithm combines the simplicity of specifying the functional form of the surface temperature history (century-long linear trends) while retaining the power of the Bayesian estimation incorporated in several of the AFR methods. It allows for (a) several ramps of lemperature change with different amplitudes and trend directions, (b) representation of the subsurface as a layered medium, and (c) simultaneous estimates of the steadystate heat flow and the long-term mean surface temperature, along with the interval trends.

\section{Theoretical Framework}

The formulation of the FPE problem is both a simplification and an extension of the finctional space inverse formulation of Shen and Beck [1991]. In addition to representing the ground surface temperature history with a sequence of fixed interval ramp changes, we make two further simplifications: First, we treat the specific beat capacity and the heat production rate of the subsurface rocks as known quantities. This greatly reduces the size of the model to be estimated without much sacrifice, because heat capacity and heat production play only minor roles in the inverse problem [Shen and Beck, 
1992; Shen et al., 1992]. Second, although in computing the steady-state the subsurface is taken as an arbitrarily layered medium with depth-dependent thermal conductivity and heat production rate, in computing the perturbation to the borehole temperature profile doe to ground surface temperature changes the thermal diffusivity of the rocks is taken as a constant, determined by the mean thermal conductivity and mean volumetric heat capacity. This approximation allows analytical expressions in the forward calculation, without significant impact on the estimation of century-long trends.

For ramp changes in ground surface temperature, model parameters to be estimated are the ramp amplitudes and durations, the long-term mean surface temperature, the steady state basal heat flow density, and the thermal conductivities. The inverse formulation is a straightforward application of the nonlinear least squares inverse theory of Tarantola and Valette [1982a,b] and Tarantola [1988]. To avoid the trade-off between the ramp amplitude and the ramp duration [Chisholm and Chapman, 1992] and for the convenience in comparing the results, we fix the starting times of the ramps at the turning of the centuries. In so doing, we explicitly focus only on centurylong trends of the surface temperature variation. To be sure, there are other time intervals of climatologic interest, such as decadal or millennial, that one might argue are equally important. However, at the decadal scale the geothermal approach can offer little insight into climatic variability that is not already present in the meteorologic record, while for the millennial scale many boreholes are not deep enough to provide robust estimates. We feel that century-long trends effectively exploit the information available in most boreholes. Moreover, in the context of relevance to the global warming debate, the global meteorological record is only a little more than a century long, and yields to the first order the global temperature trend for only the 20th century. Although the true ground surface temperature variation in the past may not be precisely expressed by a few century-long ramps, nevertheless they comprise a reasonable and useful approximation to what we can expect to retrieve from borehole temperatures, given considerations of resolving power [e.g., Clow, 1992; Beltrami and Mareschal, 1995].

In the following sections, we present some results of a synthetic experiment with this FPE technique and some field data examples from northeast USA and southeast Canada. The synthetic experimental results of the FPE will be compared to that of the AFR technique based on the same functional space inverse theory [Shen and Beck, 1991; 1992]. Shen et al
Arbitrary Function Reconsturction

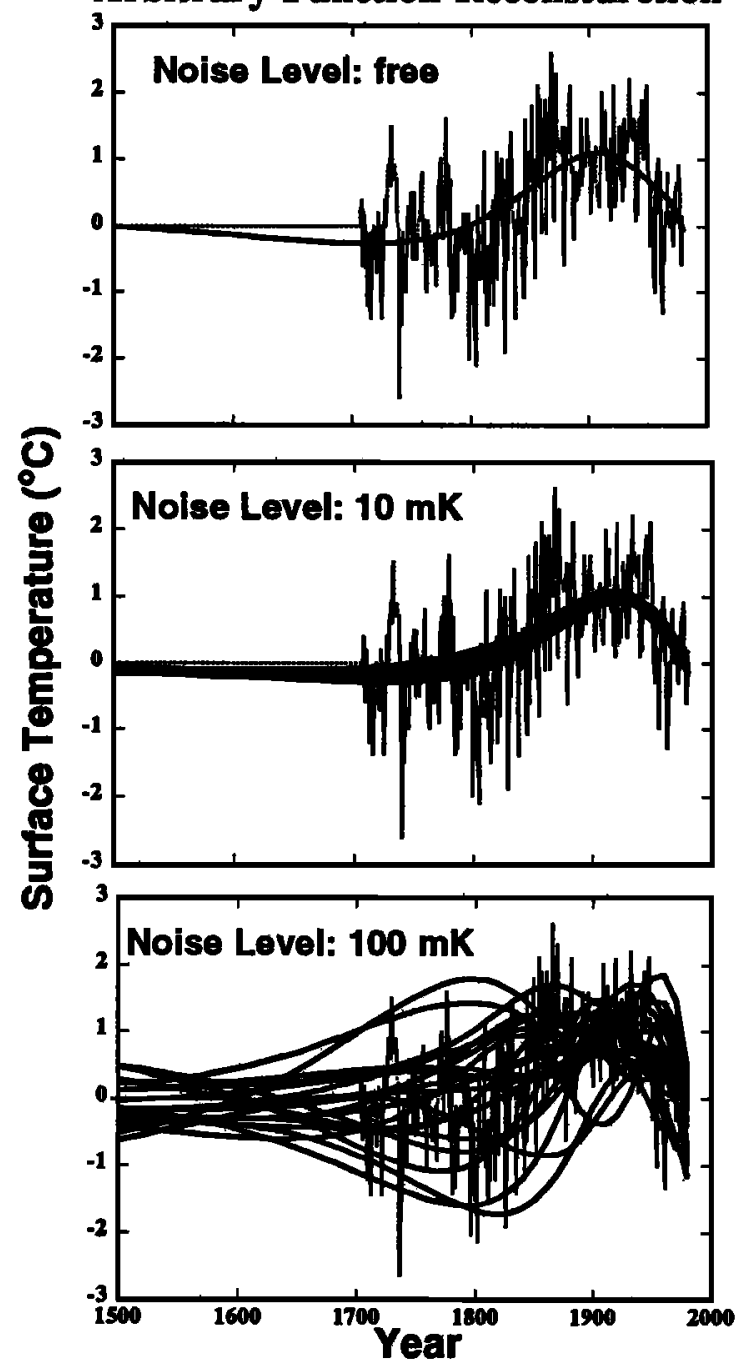

Few-Parameter Estimation
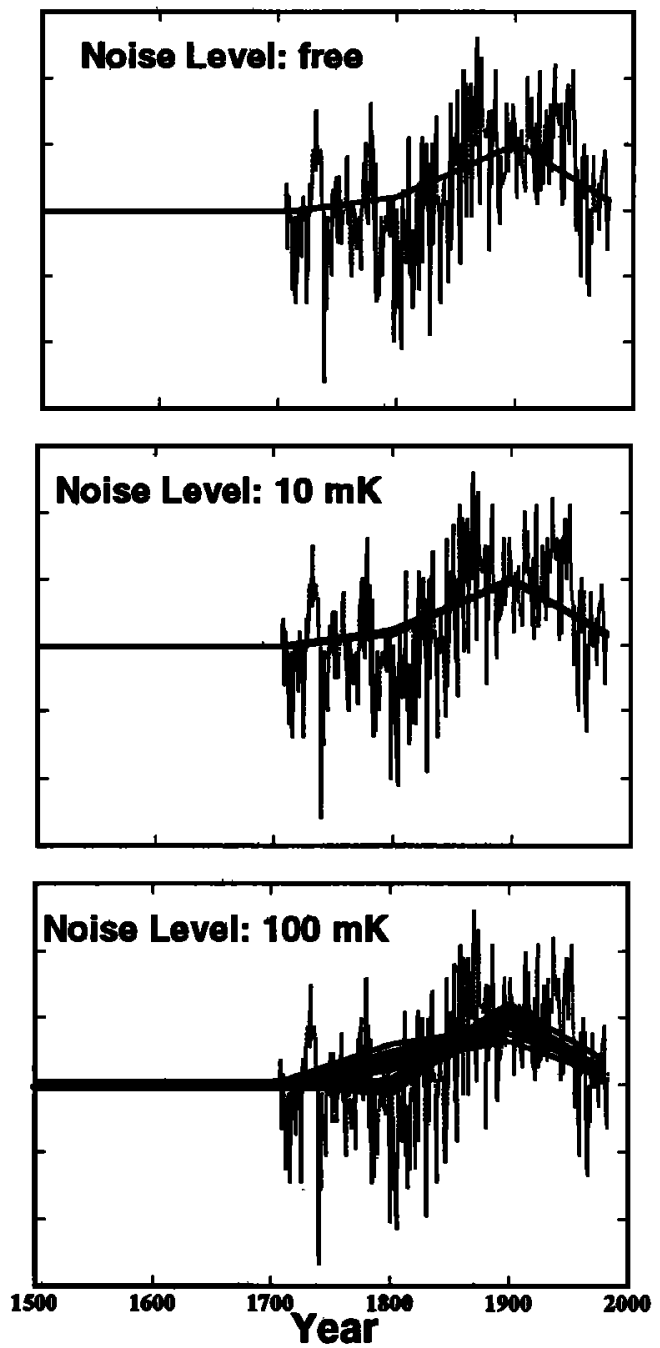

Figure 1. Comparison of the synthetic experimental results from the few-parameter estimation technique and the arbitrary function reconstruction technique at three noise levels: noise free (top), $\pm 10 \mathrm{mK}$ (middle), and $\pm 100 \mathrm{mK}$ (bottom). Dotted line shows the surface temperature signal used to generate the synthetic borehole temperatures. 
[1995a,b] have shown that the numerical constraints imposed on data processing will affoct the degree of both signal extraction and noise suppression and, hence, a ground surface temperature reconstruction. In this paper, we consistently use a set of constraints suggested by Shen et al. [1995a] and our unpublished experiments. This set of constraints is determined in terms of the relative number and spatial density of the borehole data, and is considered optimal for the noise level encountered in typical field settings.

\section{Synthetic Experiments}

One of our synthetic experiments is based on the annual series of surface air temperature of De Bilt in the Netherlands. This record covers an interval from 1705 to 1980 , one of the longest meteorological records in the world. Although technically this air temperature time series may not be without flaws because of instrumental and site changes over the years, it serves well for the purpose of illustrating the FPE method. We used this annual air temperature time series to generate a synthetic "climate-perturbed" borehole temperature profile. Different levels of random noise were then added to the profile, and the data were then inverted with both the FPE and AFR methods. In the FPE method we used a three ramp model with starting times at 1700,1800 , and 1900 , respectively. We considered three gaussian noise levels in these synthetic experiments: (a) noise free, (b) $\pm 10 \mathrm{mK}$ (standard deviation), and (c) $\pm 100 \mathrm{mK}$ respectively representing idealized, excellent, and fair field observations. At each noise level, we generated twenty synthetic borehole temperature profiles each with a different realization of noise sequence, and inverted them, using a standard set of inversion constraints throughout. For comparison, results from both FPE and AFR techniques are shown side by side in Figure 1. At the noise-free level, both FPE and AFR techniques capture the general features of the true surface temperature history very well. At the $10 \mathrm{mK}$ noise level, the twenty ground surface temperature histories inferred by the FPE remain almost identical; and although there are slight differences among the AFR results, each single AFR inversion has captured the essential features of the true surface temperature history reasonably well. However, when the noise level is further increased to $100 \mathrm{mK}$, differences in isolating climate-related information with the two approaches becomes apparent. Individual inversions by the FPE still give a good estimate of surface temperature change in the past, with results from different profiles comparing fairly well with each other. By contrast, the results from the AFR are much more scattered, and there is a greater chance that a single AFR may misinterpret the ground surface temperature history. AFR is of course capable of yielding better results with much less scatter than those shown in Figure 1, but achieving a more consistent set of reconstructions requires an adjustment of inversion constraints at each noise level [Shen et al., 1995a], i.e., proper use of the AFR requires greater user sophistication. By contrast, the FPE functions reasonably well using a standard set of inversion constraints over a wide range of noise-levels, because the form of the surface temperature variation is prespecified. It is therefore simpler to use and more immune to improper application than is the AFR, an attribute that commends its use as a standardized inversion procedure.

\section{Field Examples from USA and Canada}

We invert seventeen sets of borehole data from eleven sites in northeast USA and southeast Canada to serve as field

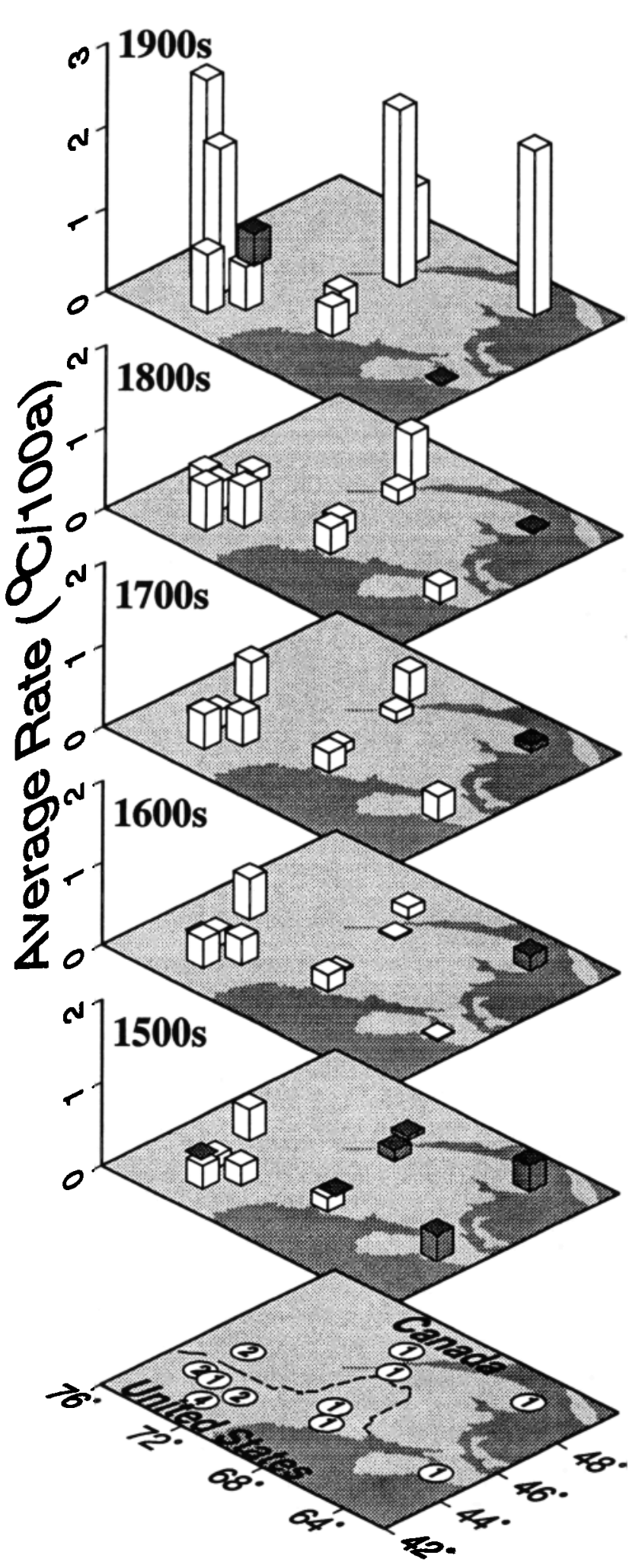

Figure 2. Location map (bottom) of selected sites in northeast USA and southeast Canada and the inferred average century rates of surface temperature change for $1500 \mathrm{~s}, 1600 \mathrm{~s}, 1700 \mathrm{~s}$, 1800 s, and 1900 s (from second to the bottom). The number inside a circle in the location map is the number of temperature profiles at the corresponding site. The rate of surface temperature change is shown by the height of the column in the upper five panels. White represents warming, and black represents cooling. 
examples of the FPE technique. The eleven temperature profiles from northeast USA include six logs measured in New England in 1964 and 1965 [Birch et al., 1968; Decker and Roy, 1974], two logs taken in Maine in 1978 by Decker [Decker, per. comm.], and profiles of three of the New England boreholes relogged in 1991 [Stepaniak et al., 1992]. The six temperature logs in southeast Canada are among the field data analyzed by Wang et al. [1992] and subsequently reprocessed by Shen et al. [1995a] for ground surface temperature history reconstruction. In the analysis of the field data, we used a five ramp model to represent the century long trends of surface temperature change. The six panels of Figure 2 from bottom to top respectively show the location map of the selected sites and the inferred average rates of surface temperature changes for the 16th through 20th centuries. Despite the diminished resolution towards the more remote past because of the attenuation of the climate signal in nature and the necessary smoothing imposed by the inversion procedures, these results show that cooling was not an unusual phenomenon in the eastern part of this region in the 16th century. However in subsequent centuries, particularly in the 20th century, warming has become the dominant phenomenon. These results are comparable to earlier results obtained with an AFR technique [Pollack et al., 1993; Shen et al., 1995a]. Figure 2 also illustrates the simplicity of display that derives from the FPE technique, allowing synoptic views of both spatial and temporal trends. Additionally, century-long trends are easily tabulated quantities that make borebole results readily available for use by meteorologists, climate modellers and those estimating temperature trends by proxy methods.

Acknowledgments. Wo thank Kelin Wang and an anonymous reviewer for constructive comments on the manuscript. The metecrological record of De Bit in the Netherlands was provided by Lenka Kucerova of the Czech Academy of Sciences. This research is supported in part by NSP grant ATM-930008.

\section{References}

Beck, A.E., P.Y. Shen, H. Beltrami, J.-C. Mareschal, J. Safanda, M.N. Sebagenzi, G. Vassecur, and K. Wang, A comparison of five different analyses in the interpretation of five borehole temperature data sets, Palaeogeogr. Palaeoclimatol. Palaeoecol, 98, 101-112, 1992.

Beltrami, H., A.M. Jessop and J.-C. Mareschal, Ground temperature histories in eastern and central Canada from geothermal measurements: Evidence of climate change, Palaeogeogr. Palaeoclimatol. Palacoecol, 98, 167-183, 1992.

Beltrami, H. and J.-C. Mareschal, Recont temperature changes in eastexn Canada inferred from goothermal measurements, Geophys. Res. Lett., 18, 605-608, 1991.

Beltrami, H. and J.-C. Mareschal, Resolution of ground temperature histories inverted from borehole temperature data, Global Planet. Change Sect., 11, 57-70, 1995.

Birch, F., R.F. Roy, and E.R. Decker, Heat flow and thermal history in New England and New York, in Studies of Appalachian Geology: Northem and Maritime, eds. E.B. White and E-an Zen, pp. 437-451. Interscience, New York, 1968.

Carslaw, H. S. and J.C. Jaeger, Conduction of Heat in Solids, 2nd ed. 510 pp., Oxford University Press, 1959.

Cermak, V., Underground temperature and inferred climatic temperature of the past millennium, Palaeogeogr. Palaeoclimatol. Palaeoecol., 10, 1-19, 1971.

Chisholm, T. J. and D.S. Chapman, Climate change inferred from borehole temperatures: An example from western Utah, J. Geophys. Res., 97, 14155-14176, 1992.
Clauser, C. and J.-C. Mareschal, Ground temperature history in central Europe from borehole temperature data, Geophysical Joumal Intemational, 12J, 805-817, 1995.

Clow, G. D., Temporal resolution of surface temperature histories inferred from borehole temperature measurements, Palaeogeogr. Palaeoclimatol. Palaeoecol., 98, 81-86, 1992.

Decker, E.R. and R.F. Roy, Besic heat-flow date from the castern and werstern United States, Open-File Rep., 74-9, pp.7-1--7-90, U.S. Geol. Surv., 1974.

Harris, R.N. and D.S. Chapman, Climnte change on the Colorado Plateau of eastern Utah inferred from borehole tempeatures, $J$. Geophys. Res., 100, 6367-6381, 1995.

Lachenbruch, A. H. and B.V. Marshall, Changing climate: Geothermal ovidence from permnfrost in the Alaskan Arctic, Science, 234, 689 696, 1986.

Lewis, T. J. and K. Wang, Influence of terrain on bedrock temperatures, Palaeogeogr. Palaeoclimatol. Palaeoecol., 98, 87-100, 1992.

MacAyeal, D. R., J. Firestone, and E. Waddington, Paleothermometry by control methods, J. Glaciology, 37, 326-338, 1991.

Pollack, H. N., S. Huang, E.R. Decker, and D. Stepaniak, Ground surface temperature histories reconstructed from borehole temperatures from northeastern USA, EOS Trans. Am Geophys. Union, 74(16) Supplement, p.89 (abstract), 1993.

Shen, P.Y. and A.E. Beck, Least squares inversion of borehole temperature measurements in functional space, J. Geophys. Res., 96, 19,965-19,979, 1991.

Shen, P.Y. and A.E. Beck, Paleoclimate change and heat flow density inferred from temperature data in the Superior Rrovince of the Canadian Shield, Palaeogeogr. Palaeoclimatol Palaeoecol., 98, 143165, 1992.

Shen, P.Y., K. Wang, H. Beltrami, and J.-C. Mareschal, A comparative study of inverse methods for estimnting climatic history from boreholo temperature datm Palaeogeogr. Palaeoclimatol. Palaeoecol., 98, 113-127, 1992.

Shen, P.Y., H.N. Pollack, S. Huang, and K. Wang, Effects of subsurface heterogeneity on the inference of climate change from borehole temperature data: model studies and field examples from Canada, $J$. Geophys. Res., 100, 6383-6396, 1995 .

Shen, P.Y., H.N. Pollack, and S. Huang, Inference of ground surface temperature history from borehole temperature data: a comparison of two inverse methods, Subrnitted to Palaeogeogr. Palaeoclimatol. Palaeoecol., 1995b.

Stepaniak, D.L., E.R. Decker, and H.N. Pollack, Borehole temperature changes over 28 years: implications for heat flow hydrologic and climate change, EOS Trans. Am. Geophys. Uniom 73(43) Supplement p.70 (abstract), 1992.

Tarantola, A., Theoretical background for the inversion of seismic waveforms, including elasticity and attenuation, Pure Appl. Geophys., 128, 365-399, 1988.

Tarantola, A. and B. Valette, Generalized nonlinear inverse problems solved using the least squares criterion, Rev. Geophys., 20, 219-232, 1982 .

Tarantola, A. and B. Valette, Inverse problems = Quest for information, J. Geophys., 50, 159-170, 1982b.

Wang, K., Estimation of ground surface temperatures from borehole temperature data, J. Geophys. Res., 97, 2095-2106, 1992.

Wang, $\mathbf{K}$ and T.J. Lewis, Geothermal evidence from Canada for a cold period before recent climatic warming, Science, 256, 1003-1005, 1992.

Wang, K., T. J. Lewis, and A. M. Jessop, Climatic changes in central and eastern Canada inferred from deep borehole temperature data, Palaeogeogr. Palaeoclimatol. Palaeoecol., 98, 129-141, 1992.

Shaopeng Huang and Henry N. Pollack, Department of Geological Sciences, 2534 C. C. Little Building, University of Michigan, Ann Arbor, MI 48109-1063. (c-mail: shaopeng @umich.edu; hpollack@umich.edu).

Po Yu Shen, Department of Earth Sciences, University of Western Ontario, London, ON, Canada N6A 587.

(Received August 21, 1995; revised November 20, 1995; accepted November 22, 1995.) 